\title{
The Development of Teacher Development Innovation for Enhancing Students' Learning Achievement in Rajaprajanugroh 50 School under the Office of Special Education Administration
}

\author{
Narongrat Choktanaprasit ${ }^{1}$, Chalard Chantarasombat ${ }^{2} \&$ Pha Agsonsua $^{2, *}$ \\ ${ }^{1} \mathrm{Ph} . \mathrm{D}$. Candidate in Educational Administration, Thailand \\ ${ }^{2}$ Faculty of Education, Northeastern University, Khon Kean, Thailand \\ *Correspondence: Faculty of Education, Northeastern University, Khon Kean, Thailand. Tel: 66-4322-2959. E-mail: \\ narongratkku@gmail.com, E-mail: chalard10@gmail.com
}

Received: February 29, 2020

Accepted: April 8, $2020 \quad$ Online Published: April 22, 2020

doi:10.5430/wje.v10n2p203

URL: https://doi.org/10.5430/wje.v10n2p203

\begin{abstract}
The objectives of this research were to: 1) create and specify the achievement goal of developing the innovation for enhancing the learning achievement of schools, 2) develop the potentiality of teachers and educational staffs in enhancing learning achievement of schools with the application of the ESC in coaching and mentoring, 3) monitor and enhance learning achievement of schools, The development and participatory action research were employed through the application of ESC. Research tools consisted of the learning activity package, teaching observation forms, narrative recording form, lesson plan analysis recording form, teaching reflection recording form, and criteria of activity implementation. Statistics used were percentage, mean, standard deviation, effectiveness index and the statistics in hypothesis testing. The results revealed that: 1) The school performed learning transformation project to enhance students' learning achievement in terms of memorandum of cooperation with the networking schools. 2) The results of the overall development of the potential of teachers and school administrators showed: (1) the efficiency of both activities and tests were 90.96/81.02 which were higher than the committed standard 80/80, (2) the effectiveness index after training was higher than before at 0.7480 showing an increase of knowledge of $74.80 \%$, (3) the mean score of after training was significantly higher than before at the level of 0.01 , and (4) there were no statistically significant differences in mean scores on learning retention. 3) The monitoring performance of co-researchers showed the increase in knowledge, practicing, and feeling. 4) The Professional Learning Community building started up with (1) collaboration of all stakeholders, (2) studying and analyzing information, (3) specifying target and indicator, (4) planning and building up a network, (5) presenting learning co-design, (6) trying out innovation after the ESC actions, and (7) sharing the ESC in the school and school network.
\end{abstract}

Keywords: innovation, enhancement of learning achievement, excellent supervision clinique: ESC, professional learning community: PLC, school as leaning community: SLC

\section{Introduction}

\subsection{Rationale}

The Reform of Educational Management based on the Educational Service Area Office, the student-centered instructional management, and the students' learning during the $21^{\text {st }}$ century, could happen everywhere and at any time. According to the Constitution of the Kingdom of Thailand 1997, the educational law as the National Education Act 1999, was passed. Later on, there was a combination between Primary Schools and Secondary Schools into the Educational Service Area Office. The group with responsibilities in supervision, following up, and evaluation in Educational; Management. There was a committee in following up, checking, evaluating, and educational supervision. (CCES) for considering, enhancing, and promoting the work practice by mechanism in work practice of educational supervisors in group of supervision, following up, and evaluating the Educational Management since then. During the past decade, it was found that the Educational Quality including the learning achievement, the Educational Quality Ranking of Thailand and various countries, and the process as factors in Educational Quality Development, were likely to be lower. In dimension of Educational Supervision Process as an important reform 
process for quality improvement, consisted of complex problems. It was found that the Educational Supervisors based on framework of specified function and duty, did not follow the role and function of Educational Supervisors. There were no classroom supervision networks. How to develop the strength of Educational Supervision as well as participation in shared educational supervision among the Educational Supervisors, school group, and schools based on approach that "Supervising the Route to Excellence (SRE)" (Deanery, 2015) using the Educational Supervision Process for moving the development model into strength in School based In-service Training: (SIT) and Classroom based Management (CBM) by using the Institutional Research Process until becoming the various systems that should be done in class. Being major data base and developmental base led to be Professional Learning Community (PLC) and associate strategic planning, action plan of school and community leading to the Educational service Area Office as the mechanism of Office of the basic Education Commission, would be reference as Model, A Case Study should be developed, and the findings should be utilized.

The work in providing people's Education was very challenging for which the cooperation from every sector in Thai society was truly needed. Because the output from Education would be indicators of national success. It indicated the development in human potentiality. Therefore, the Educational Management should be performed carefully with good planning, and be a system for every person's competency for understanding in the same way in order to accomplish shared planning objective. Specifically, in the present, the learning skill age during the $21^{\text {st }}$ century, the instructional management was dramatically changed. Sumon Amonwiwat (2009, p.8) stated that "From teachers' standing in front of the classroom, using the lecture as major technique, in the present, they had to know how to adjust their teaching method," not to focus on theoretical approach only. They had to change the instructional context as well as instructional role so that their students would know how to find the answers and question by themselves."

The former overall data indicating the assessment of national learning achievement in Pratomsuksa 6 Students and Secondary School level of schools under the Special Education Administration, Office of the Basic Education Commission, has continuously been considerably lower than the standard criterion until now especially in Science, Mathematics, and English Language Learning Substances. So, it was the problem of an emergent need to be solved by one in Educational Situation. Therefore, it was necessary to develop the innovation for enhancing the school's learning achievement in order to solve the problem of low learning achievement by integrating the quality classroom as well as quality school of students in the $21^{\text {st }}$ century to be congruent with the $12^{\text {th }}$ Issue of National Economic and Social Development Plan (2017-2021), and 20 years National Education Development Plan (2017-2036) as the complex thinking integration and various practices. The new movement was created to be secure, prosperous, and sustainable development through participation of Civil State Power by appropriate and congruent technology of Sufficiency Economy Philosophy in order to obtain added value and Educational Quality to be Thailand 4.0 both in direct and indirect ways including: the creative thinking, innovation, Science, Technology, and Research and Development. Since 2016 budget year until now, the Special Educational Work Management held the workshop training as guideline for enhancing the students' learning achievement in Rajaprajanugroh 50 Schools, and implementing "the Project for Enhancing the Students' Learning Achievement," there were attendants including the school administrators, academic work heads, representative teachers in Primary Schools and Secondary Schools under jurisdiction from the whole country. The conference agreed that since the academic year 2018-2019, the innovative project for enhancing school's learning achievement by participatory work from public sector, private sector, and people sector should be established. The Higher Education Institutions should be consultants for focusing on participatory learning and cooperation. The goal was quality classroom in school by applying the supervision for excellence by supervision and coaching, and moving into dimension of construction for Professional learning Community (PLC) of schools under jurisdiction to be secure, prosperous, and sustainable development.

\subsection{Research Questions Are As Follows:}

1) How to synergize the participants' cooperation in determining the objectives, indicators of success, enhancement of learning achievement of Rajaprajanugroh 50 School, to be appropriate including the common movement mechanism?

2) According to the potential development of teachers in Rajaprajanugroh 50 School, for knowledge, practice, and attitude based on major learning packages, what would be findings of development in efficiency, process/effectiveness of outcome, effectiveness index, and learning retention?

3) How to network of professional learning community from preimplementation, during implementation, and post implementation in school level and team working of network group would be able to implement according to the activity work plan based on agreement? How to be continuous? 


\subsection{Research Objectives Are As follows:}

1) To create and specify the achievement goal of developing the innovation for enhancing the learning achievement level in Rajaprajanugroh 50 School.

2) To develop the teachers' potentiality in enhancing the students' research achievement level in Rajaprajanugroh 50 School, by applying the Educational Supervision Practice for Excellence into suggestion and coaching.

3) To monitor and enhance learning achievement level in Rajaprajanugroh 50 School, the development and participatory action research were employed through application of ESC.

4) To construct and develop Professional Learning Community in Rajaprajanugroh 50 School.

\subsection{The Delimitation of Research Are As Follows:}

1) Research participants included: 1.1) one researcher, 1.2) twelve co-researchers including (1.2.1) one school administrators, (1.2.2) nine classroom teachers in pratomsuksa 1-6 in school, (1.2.3) one educational supervisor and (1.2.4) one academic from a higher educational institution.

2) The research conceptual framework, the creative thinking and participatory working were analyzed as 3 issues of cooperative participants including: (1) the supervision for excellence leading to suggestion and coaching for knowledge management in major learning substances, (2) the participatory working by associating the movement of teachers, school administrators, educational supervisors, and academics from higher educational institution into supervision network for excellence, and (3) the construction for professional learning community of target group schools in the area, Rajaprajanugroh 50 School, Khon Kaen province, under the office of special education administration, office of the basic education commission.

2.1) The Educational Supervision Clinique: The route to excellence, the suggestion and coaching of school was Wales Deanry (2014) including the Educational Supervision Clinique: the route to excellence. (Chalard Chantarasombat and Nothai Udomboonyanupab, 2017), the enhancement of learning achievement by using the supervision into suggestion and coaching as shown by Figure 1.

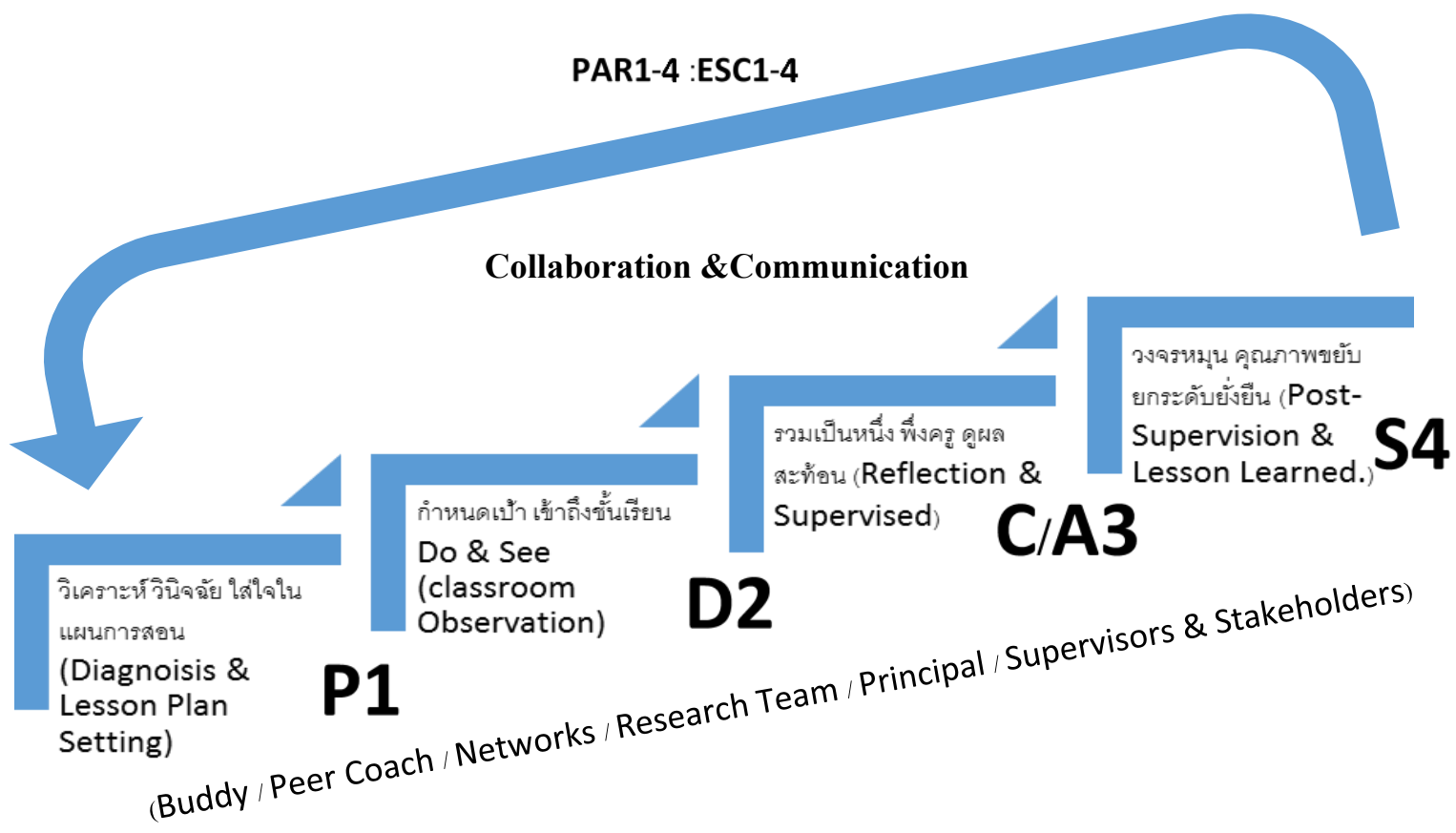

Figure 1. The Conceptual Framework of Educational Supervision: The Route to Excellence into Suggestion and Coaching. (Chalard Chantarasombat, 2017)

The route to excellence referred to process in collaborative working by teachers, educational supervisors, and school administrators, the suggestion and coaching, demonstration or explanation. After the instructional management during instructional process being collaboratively designed by 4 steps of collaborative work practice (Chalard Chantarasombat and Nothai Udomboonyanupab, 2016) as follows: 
1.1) The Analysis, Diagnosis \& Concentration in Designing the Lesson Plan and Learning activity Setting.

1.2) The Step of Do \& See: Classroom Observation, the goal setting and Classroom access.

1.3) The Step of Reflection \& Supervision included to be unique by depending on the teachers and viewing the reflection.

1.4) The Step of Post-Supervision \& Cooperative Lesson Development, the quality cycle enhanced the continuous and sustainable spiral level.

2) The Participatory Action Research: PAR, led to Professional Learning Community: 1) Wichan Panich, (2013) (The Way to construct students' learning during the $21^{\text {st }}$ century), 2) Wichan Panich, (2013) (How is learning occurred?, 3) Wichan Panich, (2013) (The teachers for students to construct reverse classroom), 4) Wichan Panich, (2013) (Have fun with learning during the 21 $1^{\text {st }}$ century), 5) Wichan Panich, (2014) (Teaching the students to be good, 6) Wichan Panich, (2015) (Transformative Learning), and 7) Wichan Panich, (2016) (Teacher's happy life into learning community). According to both techniques of conceptual framework, it could be outlined into Professional Learning Community as shown in Figure 2.

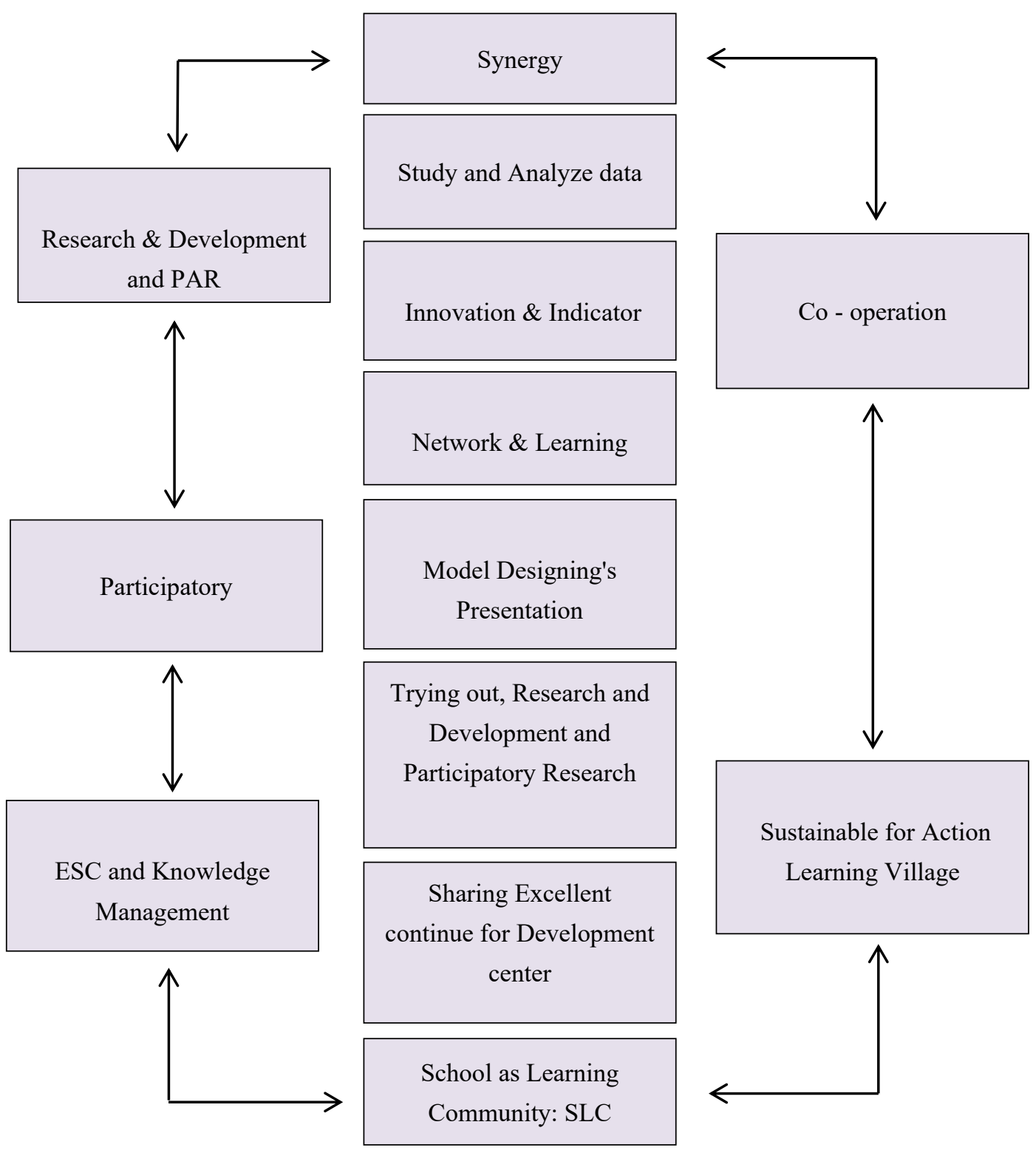

Figure 2. Conceptual Framework of Research and Development for Professional Learning Community Model (Chalard Chantarasombat, 2017) 


\section{Research Methodology}

The study was divided into four phases:

Phase 1: Study the success goal was constructed and specified, the innovation was developed for enhancing the students' learning achievement.

1) The readiness preparation was classified as follows: 1.1) the issues of development for project planning were collaboratively were specified. 1.2) the current situation, problem, and need for teacher development of Rajaprajanugroh 50 School, Khon Kaen province, were collaboratively studied and analyzed by the workshop.

2) The current situation of problem was studied. In addition, the issues of were specified.

Phase 2: The teacher development training for enhancing the students' learning Achievement by applying learning package: the Educational Supervision Clinique: The Route to Excellence leading to supervision and coaching, and Professional learning Package.

1) The rationale, theoretical approach and related literature of innovation for enhancing the school's learning achievement were studied. In addition, the learning sources of best practice were surveyed.

2) The innovation for enhancing and school's learning achievement was constructed and developed as two Modules of Learning Package.

3) The workshop was provided for school teachers.

4) The field trip study was provided from 3 best practice schools including: Rajaprajanugroh 15 School, Rajaprajanugroh 30 School, and Rajaprajanugroh 47 School.

5) The classroom teaching was studied and demonstrated as Community Group.

6) The innovative project for enhancing the learning achievement by using the Educational Supervision Clinique: The Route to Excellence, was established by school.

Phase 3: The findings of implementation for enhancing the students' learning achievement in project Rajaprajanugroh School,50 Khon Kaen Province, under the Office of Special Education Administration.

1) The enhancement of school's learning achievement was followed up.

2) The enhancement of learning achievement from workshop was followed up.

Phase 4: The Professional Learning Community: PLC was constructed and developed.

1) The co-researchers implemented innovative teacher development project for enhancing the learning achievement in Rajaprajanugroh 50 School, Khon Kaen province, under the Office of Special Education Administration. "through the application of Educational Supervision Clinique: The Route to Excellence into supervision and coaching" during the first semester of 2019 academic year. The Model of Professional Learning Community (PLC) was constructed and developed. The participatory synergy was developed by school administrators, teachers, and educational supervisors.

2) The innovative project for enhancing the school's learning achievement "through the application of Educational Supervision Clinique: the Route to Excellence into supervision and coaching" in pattern of usage in Educational Supervision Clinique: the Route to Excellence leading to supervision and coaching by constructing the Professional Learning Community (PLC) continuously during the second semester of 2019 academic year.

\subsection{Research Instruments}

There were two kinds of research instruments as follows:

1) There were two Learning Packages for enhancing the learning achievements, evaluated by the experts including the Congruency, Propriety, Feasibility, and Utility for cooperative participants of school in "The Highest" level.

2) The instruments for data collection:

2.1) The Observation Form and Record Form were validated for it Content Validity and Construct Validity by the experts.

2.2) The Learning Achievement Test was 4 alternatives, one issue each Package, and another one overall test, total of 3 issues. The items of every test consisted of IOC ranged from 0.50 to 1.00 . The Item Difficulty ranged from 0.40 to 0.80 . The Item Discrimination ranged from 0.20 to 0.60 . Furthermore, the Reliability of total issue was $=0.85,0.83$, $0.87,0.86$, and 0.84 
2.3) The Questionnaire of Satisfaction on Innovation for Enhancing the Students' Learning Achievement, the Item Discrimination $\left(\mathrm{r}_{\mathrm{xy}}\right)$ ranged from 0.32 to 0.83 . Moreover, the Reliability of total issue was $=0.93$.

\subsection{The Statistic in This Research}

1) Basic statistics consisted of the Percentage, Mean, and Standard Deviation.

2) The statistic using for findings the instrument quality consisted of the searching for Validity and Discrimination of Learning Achievement Test by using the Index of Congruence (IOC), Difficulty (P) of Learning Achievement Test, the Reliability of Learning Achievement Test, the Reliability of Satisfaction Questionnaire of Co-researchers by searching for the Alpha Coefficient.

3) The statistic using for finding the Efficiency of Learning Package, the Effectiveness Index (EI) of development for teachers, school administrators, and educational supervisors learned through innovation for enhancing the students' learning achievement in Rajaprajanugroh 50 School by applying the Educational Supervision: The Route to Excellence into Supervision and Coaching.

4) The statistic using for hypothesis testing consisted of the t-test (Dependent Samples)

\section{Results}

The operation results were as follows:

1) Rajaprajanugroh 50 School, Khon Kaen Province, was able to analyze the current situation, problem, and need for plying the Educational Supervision: The Route to Excellence (ESC).

1.1) Rajaprajanugroh 50 School, Khon Kaen Province, developed the process for enhancing the learning achievement by using Educational Supervision Clinique: The Route to Excellence, trying out and demonstrating the internal supervision of school by using 4 steps of Educational Supervision Clinique: The Route to Excellence (ESC), including: the study of lesson plan, the goal setting, the teaching practice, observing the collaborative learning reflection by staffs inside school and outsiders, reviewing the enhancement in body of knowledge, improving the lesson plan for trying out in the same class level. As a result, the teachers had self-confidence and were able to develop relationship as a teamwork and open classroom leading to group working as well as Professional Learning Community in basic level.

1.2) Rajaprajanugroh 50 School, Khon Kaen Province studied the findings of development and usage of Educational Supervision Clinique: the Route to Excellence (ESC), by learning from learning sources, school focusing on learning during the $21^{\text {st }}$ century, the teachers learned together with their students as well as with their co-workers and school administrators, and outsiders like educational supervisors, by field trip study from 3 best practice schools: Rajaprajanugroh 15 School, Rajaprajanugroh 30 School, and Rajaprajanugroh 47 School. According to the conclusions of lesson from field trip study in both of before and after the field trip study, the teachers could enhance their body of knowledge which would cause their school to be able to have competency and skill in being the Professional Learning Community (PLC\& SLC).

1.3) Rajaprajanugroh 50 School, Khon Kaen Province, has developed the supervision and coaching systems which could support learning reform to the students in school of learning reform project to the students emphasizing on innovation for enhancing the students' learning achievement. Since the teachers learned together with their students as well as their co-workers and school administrators in all of 5 major learning substances. The major target group focused on Pratomsuska 1-6.

2) The potential development of learning reform to the students of school administrators and teachers based on innovative project for enhancing the learning achievement "through the application of Educational Supervision Clinique: The Route to Excellence (ESC), by supervision and coaching," was the efficient and effective development, in overall and each sub-learning packages as followings:

2.1)The overall efficient and effective development: (1) the efficiency of practice process/outcome efficiency, the Mean values of percentage were $=90.69 \%$, and $81.02 \%$, (2) the effectiveness index after learning, the posttest knowledge was significantly higher than pretest knowledge $=74.80 \%$, (3) the comparison of Mean values, the posttest Mean was significantly higher than the pretest Mean at 0.01 level, and (4) the learning retention after two weeks of training, there were no significant differences between the Mean values of knowledge.

2.2) The efficient and effective development of each package of the two packages, was as follows: (1) Learning Package 1, the Educational Supervision Clinique: The Route to Excellence (ESC), based on innovative project for 
enhancing the learning achievement, efficiency of practice process/outcome effectiveness, the Mean values of Percentage was $=85.78 / 85.83$ which was higher than the specified criterion $80 / 80$. (2) Learning Package 2, the Educational Supervision Clinique: The Route to Excellence (ESC), based on innovative project for enhancing the learning achievement, efficiency of practice process/outcome effectiveness, the Mean values of Percentage was = $88.83 / 84.72$ which was higher than the specified criterion $80 / 80$.

2.3) The teachers' knowledge after learning through innovation for enhancing the students' learning achievement, "by the application of Educational Supervision Clinique: The Route to Excellence (ESC), into Supervision and Coaching," was significantly higher than before learning at 0.01 level. Besides, the learning retention, the Mean values of learning achievement from the first measurement through immediate measurement after training, and the Mean value of learning achievement from the second measurement two weeks after training, there were no significant differences.

2.4) In overall, the school administrators, teachers, and educational supervisors participating in the project, their satisfaction on innovative project for enhancing the school's learning achievement "by the application of Educational Supervision Clinique: The Route to Excellence (ESC), into Supervision and Coaching," was in "The Highest" level. The overall Mean value of satisfaction was $=4.60$. In addition, the Standard Deviation was $=0.52$.

3) The enhancement of students' learning achievement in Rajaprajanugroh 50 School, under Special Education Administration, by the application of Educational Supervision Clinique: the Route to Excellence (ESC), into Supervision and Coaching, was appropriate through the usage of school staffs including the internal supervision of school administrators as well as leading teachers and collaborative development teachers, and outsiders including the continuous supervision, both of individual and group supervision, and online supervision. Furthermore, the development was viewed thoroughly by using the Before Action Review (BAR), During Action Review (DAR), and After Action Review (AAR) through learning by doing. The project had agreement in classroom real practice. The school had to establish a working plan in learning activity between teachers-teachers, learning together between teachers and students, and learning together between teachers and school administrators. The Educational Supervision Clinique: The Route to Excellence (ESC) into Supervision and Coaching, was tried out. Each learning substance used the Educational Supervision Clinique: The Route to Excellence (ESC) into Supervision and Coaching, as major Component of learning into Practitioner community (COP), and shared learning in school level as well as different school level. The Cooperative Participants, Self-confidence, Interpersonal Skill and Relationship, and appropriate administration and development, were developed.

4) For development of Professional learning Community (PLC), there were Propriety and Congruence with context and local situation, participatory working in new dimension from development of quality classroom as well as quality school leading to the development of cooperation, synergy of model teachers, model school administrators, target group supervisors. Consequently, the Educational Supervision Clinique: The Route to Excellence (ESC) into Supervision and Coaching, was occurred. Moreover, the knowledge management led to development of Professional learning Community (PLC) Model by applying the innovation for enhancing the school's learning achievement through construction of leading academics in major Learning Substances, enhancement of knowledge level into supervisors and coaches. There were 7 steps of implementation including: (1) the participatory synergy, (2) the data study and analysis, (3) the situation and index construction, (4) the network planning and development, (5) the presentation of design for basic learning management implementation, (6) the trying out and enhancement of overall body of knowledge/professional learning community, and (7) the knowledge sharing and development into continuous learning source including 21 sub-learning activities as follows: 


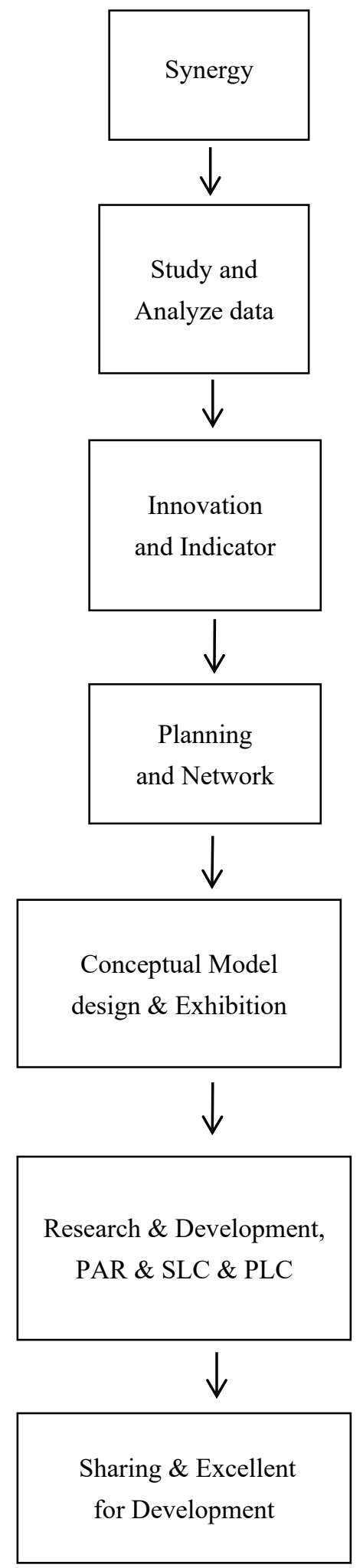

- Synergy of Teacher's Formal and Informal Participatory Synergy.

- Study of Current Situation and Problem in Teacher Development and Feasibility of Co-researchers.

- Development of Major Learning Package Innovation and Research in Instrument.

- Workshop for studying the current situation, problem, and need for Teacher Development.

- Determination of Issue for Teacher Development as a big picture of school.

- Establishment of Project for enhancing the learning achievement and teacher in major learning substances.

- Determination of goal for enhancing the learning achievement, indicator of success.

- Specifying the Indicator of Success.

- Establishing Project for enhancing the school learning achievement in school network group level school by applying the educational supervision Clinique (ESC): The route to excellence, and cooperation of teachers and school administrators.

- Determination of working network group for trying out the Educational Supervision Clinique (ESC): the route to excellence.

- Designing the Learning Management Plan as instrument.

- Field trip study and enhancement in body of knowledge for applying into suggestion.

- Trying out the ESC

- Following up the implementation by Administration school.

- Following up by the educational academics and supervisors.

- Following up implementation of clinic network by outside experts.

- Supervision for excellence into suggestion and coaching during and after the implementation.

- Presentation of work performance of modeled in-service teachers in individual and school levels.

- Presentation of work performance in network school level by representatives.

- Giving the certificate for persons passing the evaluative criteria.

Figure 3. Sub-Learning Activities 


\section{Discussions}

1) The school constructed and specified goal success in developing the innovation for enhancing the school's learning achievement by using tree diagram leading to cooperation based on project plan and activity of collaborative work of participants by development teachers, school administrators, and educational supervisors. Consequently, the Professional learning Community (PLC) was developed. Since the co-researchers provided learning activities from real practice until the appropriate body of knowledge was occurred leading to the participation based on interesting issues including: the shared thinking, the shared decision making, the shared planning, the shared practice, the shared checking, the shared responsibility, the shared benefit, and the shared learning. It was congruent with His Majesty the King Huipil Aduldej's, Working Principles. (Office of the Royal Development Projects Board, nd: 32) The King thought that Know to love and to be united. The individual and group had to know that before doing anything, they had to know before, know all factors as well as problems and how to solve them. In addition, they should have love to consider in solving those problems as well as to have unity in practicing. They should always consider that we could not work alone. They had to collaborate as an organization or team so that they would have energy to solve the problem very well. It was congruent with Prawed Wasee's (2002, p.21) statement that Only one person's learning is not sufficient for succeeding in that thing. Because the other persons, organizations, and related institutions did not learn. Only shared learning in practicing would be successful. It was congruent with Chalard Chantarasombat's (2016, p.9) statement that the development and company have to travel together. Therefore, everyone had to participate in every step of development with freedom and democracy. The school is a Professional Learning Community: PLC. The knowledge and comprehension should not be emphasized on. But, the collaborative learning from doing should be emphasized until it was one's habit, and able to change the individual working culture into collaboration to be occurred in school., develop self-confidence and team work's precise goal thoroughly in each academic year. Furthermore, the participatory administration and management leading to real Professional Learning Community (PLC), should be developed.

2) The teacher development in learning reform for enhancing the learning Achievement of students in Rajaprachanukroh Schools, under Special Education Administration, by applying the Educational Supervision Clinique: The Route to Excellence (ESC) into Supervision and Coaching, was the efficient and effective development. Since the innovation of Educational Supervision Clinique: The Route to Excellence (ESC) into Supervision and Coaching, was a big overall image covering 5 major Learning Substances of learning which would lead to teachers participating in development as well as school administrators viewed the significance in moving the internal supervision with pattern focusing on both of open classroom and application of student-centered learning more than in the past. (Kanit Tanyapoom et.al. 2017) Because the school administrators did not give an importance for classroom supervision as it should be. The teacher lives alone and teaches alone. There was no collaborative development. Therefore, it was difficult for teaching observation which would lead to real practice. If there were techniques and patterns in solving the school academic problems, using Chalard Chantarasombat and Nothai Udomboonyanupab' (2016, p. 6-7), the enhancement of school's learning achievement had mission to use the mechanism of system in organization's Educational Quality Development by using the Educational Supervision as a mechanism in moving for quality. It was learning by doing in working for students' learning achievement leading to critique for solving the problems in National Test to be congruent with indicators of major learning. The co-researchers including the teachers, administrators, educational supervisors, and academics agreed that the concrete implementation in problem solving to be congruent with measurement and evaluation, had to be performed. The thinking skill and learning by doing should be more emphasized on in addition to the knowledge, memory, and public mind. It was supported by Surachet Noirit and Nawatkon Homsin' (2017, p.62) that the self-awareness, mercy, kindness, and public mind could associate what one had learned and real practice in daily life, and adapt oneself for being relevant to current situation very well. Because there were participants in Education of learning community existed in school level truly. The team working did not bring the teachers' learning by doing as the principle like in former time. But, they emphasized on their students' indicators, measurement and evaluation at work site of students into students' learning management. It would affect their students' competency in implementation for their practice, knowledge, feeling, and creativity to every learning substance. It would also affect the quality learning, the school administrators, teachers, and educational supervisors participating in the project had satisfaction on innovative project for enhancing the school's learning achievement.

3) There was Propriety and Congruency with local context and situation in Development of Professional Learning Community (PLC) in school level and group network level. Since the participatory working by using organizational staffs including the school administrators, target group of school internal supervision, leading teachers, and teachers who developed and supervised, and outsiders including continuous educational supervisors in new dimension from 
work site development of quality classroom and quality school leading to development of cooperation and synergy of model teachers, model administrators, and educational supervisors viewing the development thoroughly by using Before Action Review (BAR), During Action Review (DAR), and After Action Review (AAR) from learning by doing into supervision and coaching as major components of learning Community of Practitioners (COP), and leading to shared learning in school level and different school level. The participatory participants as well as self-confidence, skill, interpersonal relationship, and appropriate administration and management leading to the Professional Learning Community: (PLC). As a result, the real Educational Supervision Clinique: The Route to Excellence (ESC) being congruent with local context and situation, was occurred. It was supported by Chalard Chantarasombat and Nothai Udomboonyanupab' (2016, p.6-7) the application of internal and external supervision, the enhancement for school's learning achievement with mission in using the mechanism of system in Educational Quality Development of organization in instructional process, administration and management process by using the Educational Supervision Process. It was supported by Wichan Panich's (2016, p.1-4) statement that the participatory model between school and community in development, consisted of 2 factors including: 6 Steps of Participatory Action Research (PAR), and the implementation of Integration in shared thinking, shared decision making, shared planning, shared doing, shared checking, shared responsibility, shared benefit, and shared learning in sub-activities. It was supported by Chalard Chantarasombat's (2010, p. 66-69) study in the Model Development in Knowledge Management of Organization, Community.The Mixed Method was to apply the Research and Development and Participatory Action Research, found that the community organization had overall satisfaction on implementation of knowledge management in community organization, in "High" level. The factors of success in Knowledge Management Model of community organization were: (1) the persons were enthusiastic for learning, (2) the usage of Leadership of researcher and co-researchers, (3) the research, (4) the opportunity being provided for co-researchers to participate in at the beginning, (5) the participatory working climate, (6) the learning process as well as practice, and (7) the mechanism for moving was the knowledge management of community organization. In summary, the former Knowledge Management Model was tried out and improved, found that it was appropriate model, the community organization had mechanism system for moving the knowledge management enhancing the community development. The persons learned and understood. They were self-confident and able to provide the knowledge management effectively. (Prapasiri Kunakam, Pamonpan Yurayat, and Chalard Chantarasombat, 2016)

\section{Recommendations}

\subsection{Recommendations for Work Development}

1) Teacher development should be consisted of knowledge and real practice in school level. It should be evaluated through supervision as well as following up in classroom level by using the Educational Supervision Clinique (ESC) innovation: The Route to Excellence, for developing the teacher's professional development to student's quality truly in school, including the learning culture, open classroom, and applying the $21^{\text {st }}$ century congruently with local context and situation.

2) The continuous working implementation for moving the learning achievement of administration and management process in school, the school administrators had to be leaders leading their teachers who had experience in training to be able to apply knowledge for constructing the Professional Learning Community in practice to be collaborative learning organization, strong organization, continuous and sustainable development based on intention, competent in working based on team's role for participating in Thailand 4.0 including School Administrator and Educational Supervisor 4.0 under jurisdiction of Basic Education Commission, Ministry of Education.

3) The outside academics participated in enhancing and promoting including the educational supervisors and instructors in higher education, should collaboratively learn to lead to the Educational Supervision Unit which would implement based on teacher's role and duty of educational supervisor concretely further.

\subsection{Recommendations for Research}

1) The research and development should be conducted by focusing on School-wide Participatory Action Research in Matayomsuksa 1-3, and Matayomsuksa 4-6 levels.

2) The Online Supervision Model of school-based collaborative network should be developed.

3) The research and development should be conducted by using the Educational Supervisor's role and function for enhancing the Educational Quality following the professional standard. 


\section{References}

Amonwiwat, S. (2009). Friendly Supervision. Bangkok: Chulalongkorn University.

Chantarasombat, C. (2010). Knowledge Management and School Management into Learning Organization. Mahasarakam: Mahasarakam University.

Chantarasombat, C. (2017). Enhancing New Age Teacher's Ability. Mahasarakam University into Nakaon Panom Area, Improving the Education into Professional Learning. Retrieved from www.onbnews.com/post/250

Chantarasombat, C., \& Chai-ma-yo, T. (2017). Learning Package 2: The Development through, Supervision and Coaching. Mahasarakam.

Chantarasombat, C., \& Udomboonyanupab, N. (2017). Learning Package 6: The Supervision Clinical Action. Mahasarakam.

Chantarasombat, C., \& Udomboonyanupab, N. (2017). Learning Package 5: The Classroom Action Research, and Participatory Action Research. Mahasarakam.

Chantarasombat, C., \& Udomboonyanupab, N. (2017). Learning Package: The Supervision and Clinical Action (2nd Ed.). Mahasarakam.

Chantarasombat, C., Udomboonyanupab, N., \& Songsri, C. (2018). The Innovation Development for Enhancing the Learning Performance of School, under Nakon Panom Primary Educational Area Office 2. Journal of Education, Mahasarakam University, 12(3), 18-55.

Ku-na-kam, P., Yurayat, P., \& Chanbrtarasombat, C. (2016). The Model of Participatory Academic Management in School under The Secondary Educational Area Office 24. Journal of Education, Mahasarakam University, $10(2), 58-70$.

Noi-rit, S., \& Homsin, N. (2017). "Contemplate Education and Development of Public Mind," The Educational Quality Development during the 21st Century, Mahasarakam. Office of the Royal Development Projects Board. (2006). His Majesty the King's Working Principle. Bangkok: Chulachomklao Royal Military Academy.

Panich W. (2006). Knowledge Management for Practitioner. Bangkok: Institute of Knowledge, Management Promotion.

Panich, W. (2013). Have fun with learning in the 21st century. Nonthaburi. SR Printing Mass Products co.ltd.

Panich, W. (2013). How is learning occurred? Bangkok: SR Printing.

Panich, W. (2013). Teachers who construct the reverse classroom. Nonthaburi. SR Printing Mass Product, co.ltd.

Panich, W. (2014). Teaching children to be good. Bangkok: Mata Printing co. ltd.

Panich, W. (2015). Transformative Learning. Nonthaburi. SR Printing Mass Products co.ltd.

Panich, W. (2016). New Future Skill: The Education for 21st Century. Bangkok: Open World Publishing, House co.ltd.

Panich, W. (2016). Teacher's Fun Life into Learning Community. Nonthaburi. SR Printing Mass, Products co.ltd.

Tanyapoom, K., Au-wong K., Jinawat A., \& Ritcharoon, P. (2017). The Model in Putting Research Policy, for Developing the Learning into Practice In Basic School. Journal of Education Mahasarakam, University, 11(3), 36-47.

Wales, D. (2016). "Developing doctors to deliver (3D)" Annual Report 2015-2016. Cardiff University.

Wales, D. (2014). "Agreement formerly known as the educational supervision tripartite" Supervising the route to excellence. Cardiff University, Heath Park, Cardiff. Retrieved from file://C:Users'ฉลาด $\% 20$ จันทรสมบัติDownloads/6\%20\%20Educational $\% 20$ Supervision $\% 20$ Agreement $\% 20$ (June $\% 20$ 2014)\%20Blank_0.pdf

Wasee, P. (2002). "Knowledge Management," The Workshop for Outlining the Pilot Project of Knowledge Management. 27 July 2002: Kanchana Buri. 